\title{
REVIEW
}

\section{A putative functional role for oligodendrocytes in mood regulation}

\author{
N Edgar and E Sibille
}

Altered glial structure and function is implicated in several major mental illnesses and increasing evidence specifically links changes in oligodendrocytes with disrupted mood regulation. Low density and reduced expression of oligodendrocyte-specific gene transcripts in postmortem human subjects points toward decreased oligodendrocyte function in most of the major mental illnesses. Similar features are observed in rodent models of stress-induced depressive-like phenotypes, such as the unpredictable chronic mild stress and chronic corticosterone exposure, suggesting an effect downstream from stress. However, whether oligodendrocyte changes are a causal component of psychiatric phenotypes is not known. Traditional views that identify oligodendrocytes solely as nonfunctional support cells are being challenged, and recent studies suggest a more dynamic role for oligodendrocytes in neuronal functioning than previously considered, with the region adjacent to the node of Ranvier (i.e., paranode) considered a critical region of glial-neuronal interaction. Here, we briefly review the current knowledge regarding oligodendrocyte disruptions in psychiatric disorders and related animal models, with a focus on major depression. We then highlight several rodent studies, which suggest that alterations in oligodendrocyte structure and function can produce behavioral changes that are informative of mood regulatory mechanisms. Together, these studies suggest a model, whereby impaired oligodendrocyte and possibly paranode structure and function can impact neural circuitry, leading to downstream effects related to emotionality in rodents, and potentially to mood regulation in human psychiatric disorders.

Translational Psychiatry (2012) 2, e109; doi:10.1038/tp.2012.34; published online 1 May 2012

\section{Oligodendrocytes}

In the adult central nervous system (CNS), glial cells refer to a set of non-neuronal cells that provide support to neurons, and that include astrocytes, oligodendrocytes, ependymal cells and microglia. Glial abnormalities are postulated to be involved in the pathophysiology of a variety of neuropsychiatric illnesses. ${ }^{1-4}$ Oligodendrocytes, the main myelin forming cells of the central nervous system, have recently begun to garner more attention owing to reports of widespread disruption of oligodendrocytes across psychiatric disorders. ${ }^{4}$ In addition, recent findings suggest that myelin constitution can influence neuronal properties in ways not previously considered, and may be a source of essential trophic and metabolic support for maintaining axonal integrity, ${ }^{5}$ thereby opening new research avenues into the functional role of oligodendrocytes in disease.

Overview of oligodendrocyte structure and function. Oligodendrocytes have a small round cell body and about four to six branching processes, which can myelinate up to 60 axons depending upon the diameter. ${ }^{6}$ Total oligodendrocyte numbers vary across brain regions ${ }^{7}$ and the local density depends on axonal density. ${ }^{8}$ Myelin consists of lipids $(70 \%)$ and a variety of proteins $(30 \%)$, including myelin basic protein (MBP), proteolipid protein (PLP) and $2^{\prime}, 3^{\prime}$-cyclic nucleotide- $3^{\prime}$-phosphodiesterase (CNP), which together represent the major protein components of myelin. ${ }^{9,10}$ When ensheathing axons, the opposing lipid bilayers are fused and then form compacted concentric layers (lamellae) around the bare axon (typically 10-100 lamellae). Functionally, mature oligodendrocytes provide critical insulation to facilitate axonal conduction by increasing the resistance and lowering the capacitance of the axonal membrane, which allows faster conduction speed in myelinated axons compared to unmyelinated axons of the same diameter. Oligodendrocytes also have a role in regulating the development and periodicity of nodes of Ranvier, spaces of bare axon, which contain ion channels critical for action potential propagation along the axon. At the ends of the internodal regions, the myelin lamellae form a tight association (septate-like junction) with the axon, termed the paranode region, with the axonal proteins Contactin and Caspr (contactin-associated protein) interacting with the glial protein NF155 to form the junction (Figure 1; reviewed in Poliak and Peles ${ }^{11}$ and Pedraza et $a l .{ }^{12}$ ). The paranode appears to have three primary roles in maintaining a stable saltatory conduction: (1) spatial separation of $\mathrm{Na}^{+}$and $\mathrm{K}^{+}$channels, (2) sealing the myelin sheath in a way that allows only selected nutrients to diffuse into the internodal periaxonal space (space between the myelin and axon) and (3) stabilization of the entire structure in the face of mechanical stressors. ${ }^{13}$ Recent reports have

Department of Psychiatry, Center for Neuroscience, University of Pittsburgh, Pittsburgh, PA, USA

Correspondence: Dr E Sibille, Department of Psychiatry, Center for Neuroscience, University of Pittsburgh, Bridgeside Point II, Suite 231, 450 Technology Drive, Pittsburgh, PA 15219, USA.

E-mail: sibilleel@upmc.edu

Keywords: depression; glia; oligodendrocyte; paranode

Received 5 March 2012; accepted 5 April 2012 
focused on the paranode region as the critical interface of communication between the myelin and the axon (see below).

\section{Techniques to identify oligodendrocyte-specific} alterations. Human postmortem studies frequently use stains for Nissl bodies and nuclei to distinguish between neuronal and glial cell populations, and close morphological examination has been used to distinguish between glial subtypes. ${ }^{14}$ However, this technique limits the distinction between different types of glial cells to morphological markers (e.g. oligodendrocytes are characterized by compact and uniformly darker nuclei). Fewer studies have examined differences in glial cell subpopulations using immunocytochemistry. Mature oligodendrocytes are derived from oligodendrocyte precursor cells (OPC), which develop in specific ventricular zones, migrate to their final site in the brain, and then differentiate. During this time, a variety of proteins are expressed marking the developmental stages of the cell, which could be utilized for immunohistochemical identification of both oligodendrocyte precursor cells and mature oligodendrocytes in postmortem subjects.

A relatively newly identified cell type expressing the proteoglycan protein nerve/glial antigen-2 (NG2) shares a common lineage with oligodendrocytes ${ }^{15}$ and resembles oligodendrocytes morphologically, ${ }^{16}$ making it difficult to distinguish NG2 + cells from oligodendrocytes. NG2 + cells express several markers common in oligodendrocyte precursor cells, including platelet-derived growth factor receptor, alpha subunit and Olig1 and Olig2, however they do not express markers for mature oligodendrocytes such as MBP, PLP, CNP and 01. ${ }^{17}$ In addition, NG2 + cells are able to fire action potentials, ${ }^{18}$ express-voltage-gated ion channels, ${ }^{19}$ and form unique contacts with neurons, oligodendrocytes and astrocytes (reviewed in Verkhratsky and Butt ${ }^{9}$ ), suggesting a unique functional role that is only beginning to be explored. Although not the focus of this review, imaging techniques provide an alternative means of investigating biological disturbances that relate to oligodendrocytes in live human subjects, as myelin sheaths form the majority of brain white matter. Magnetic resonance imaging (MRI) and diffusion tensor imaging (DTI) can detect certain parameters that relate to white matter integrity. Recently, significant improvements in resolution and analysis of imaging data have been made, ${ }^{20}$ which will allow more thorough investigations of large-scale oligodendrocyte-related alterations in live subjects.

\section{Oligodendrocyte alterations in neuropsychiatric disorders}

There is evidence for oligodendrocyte alterations across most psychiatric conditions, including but not limited to attention deficit and hyperactivity disorder, autism, bipolar disorder, major depressive disorder (MDD), Alzheimer's disease and schizophrenia (reviewed in Fields ${ }^{4}$ ). In schizophrenia, evidence for oligodendrocyte disruption has been reported using genetic, imaging and postmortem studies. Decreased oligodendrocyte-related gene expression, ${ }^{21-25}$ decreased oligodendrocyte numbers and density, ${ }^{26-28}$ and aberrant myelin morphology ${ }^{29}$ have been reported in various brain regions in postmortem tissue from subjects with schizophrenia compared to normal controls, including dorsolateral prefrontal cortex, anterior cingulate cortex, superior temporal gyrus, and hippocampus. Imaging studies using diffusion tensor imaging indicate decreased white matter integrity in similar regions that may exist prior to disease onset (reviewed in Takahashi et al. ${ }^{30}$ ). Functional investigations of oligodendrocyte genes altered in schizophrenia point toward disruptions in cell cycle activity and axoglial interactions, particularly at the node, thereby hinting at pathophysiological mechanisms. ${ }^{31,32}$ Although evidence in bipolar disorder is more limited, reports indicate similar decreases in oligodendrocyte density, ${ }^{26}$ oligodendrocyte-related genes primarily in the frontal cortex, ${ }^{25,33,34}$ and white matter abnormalities ${ }^{35}$ (reviewed in Mclntosh et al. ${ }^{36}$ and Mahon et al. ${ }^{37}$ ). Together, the current evidence in bipolar disorder and schizophrenia has led to the support of a model of disconnectivity via white matter tracts between the frontal cortex and emotion regulation regions. ${ }^{37,38}$ Thus, although some regional specificity in white matter disruptions may differentiate these disorders, it cannot be overlooked that disruption of mood regulation is a common feature in these disorders. In accord, patients with neurological disorders affecting white matter (e.g. multiple sclerosis) often display a high degree of comorbidity with psychiatric symptoms, including depression, ${ }^{39,40}$ and display similar patterns of dysregulation in transcriptome profiles, ${ }^{41}$ supporting the hypothesis of a connection between disrupted oligodendrocyte function and mood dysregulation.

Primary evidence for oligodendrocyte alterations in MDD. Primary evidence for glial alterations has been reported for most of the major glial subtypes in MDD (reviewed in Rajkowska and Miguel-Hidalgo, ${ }^{2}$ Hercher et al. $^{42}$ and Tham et $a .^{43}$ ). However, these changes are often described under a broad nonspecific 'glial umbrella', which we briefly summarize here, before focusing on oligodendrocyte-related changes in MDD. Postmortem studies of brain regions implicated in MDD report volumetric changes, ${ }^{44}$ which may potentially reflect glial alterations. For instance, studies in corticolimbic regions of MDD subjects have described reductions in glial density or glia/neuron ratio in the subgenual prefrontal cortex ${ }^{45}$ dorsolateral prefrontal cortex, ${ }^{46,47}$ orbitofrontal cortex, ${ }^{46}$ anterior cingulate cortex ${ }^{48}$ and amygdala. ${ }^{49,50}$ In addition to reduced cell density, increases in glial cell size were reported in the dorsolateral prefrontal $^{46}$ and anterior cingulate cortices ${ }^{51}$ of MDD subjects. In contrast, a recent meta-analysis reported an increase in $\mathrm{S} 100 \mathrm{~B}$, a glial marker that is expressed primarily in astrocytes, in MDD subjects compared with controls, ${ }^{52}$ suggesting that MDD may be associated with increases in glial cells. In addition, several recent studies using morphometric analyses have reported no changes in overall glial cells in the orbitofrontal cortex and dorsolateral prefrontal cortex of latelife MDD subjects, ${ }^{53,54}$ all together leaving a muddled consensus on total glial alterations in MDD.

Investigations with glial specific markers have now begun to provide insight into glial subtype-specific disruptions in MDD subjects. Decreases in several astrocytic markers (GFAP, EAAT1, EAAT2) have been described in postmortem human MDD subjects ${ }^{55-57}$ and a recent report described the 
presence of hypertrophic astrocytes in white matter of anterior cingulate cortex of depressed subjects as evidence for a state of chronic inflammation in white matter. ${ }^{58}$ Rodent studies have confirmed and augmented these findings, ${ }^{59-61}$ together suggesting a model of astrocyte-mediated dysfunction/depletion of prefrontal cortex glutamatergic cycling and homeostasis in MDD (reviewed in Valentine and Sanacora ${ }^{62}$ ). Increases in microglial density (using HLA-DR, a known microglial marker for neurodegeneration and neuroinflammation) have been reported in a variety of brain regions in psychiatric subjects who committed suicide, but normal microglial densities have been reported in nonsuicide MDD subjects. ${ }^{63}$ In contrast, decreased proliferation of microglial cells were reported in an animal model of MDD ${ }^{64}$ leaving an undefined picture of microglial alterations not only in MDD, but also in other neuropsychiatric disorders. ${ }^{65}$

Recently, research has begun to focus on oligodendrocyte and white matter abnormalities in human MDD subjects, including postmortem tissue and live subjects, using imaging approaches (reviewed in Tham et al. $^{43}$ ). Tissue level analysis using the Kluver-Barrera staining method revealed that staining intensity of deep white matter in the dorsolateral prefrontal cortex was significantly less intense in MDD subjects compared with controls. ${ }^{35}$ On a cellular level, staining of Nissl bodies using morphological cell-type determination revealed that previously reported decreases in glial cell number in amygdala and prefrontal cortex of MDD subjects could be attributed to reduced oligodendrocyte numbers. ${ }^{26,50}$ A more recent study found a decreased density of oligodendrocytes in the frontopolar cortex of human MDD subjects using a novel approach of flow cytometry on fluorescently labeled suspended nuclei. ${ }^{66}$ However, to our knowledge, no studies have examined oligodendrocyte changes in MDD subjects using immunohistochemical techniques for oligodendrocyte-specific markers.

Patterns of downregulation of oligodendrocyte-related gene transcripts have been reported in human postmortem subjects with MDD compared with control subjects in regions including the amygdala, ${ }^{67}$ the nearby temporal cortex, ${ }^{22}$ the dorsolateral prefrontal cortex ${ }^{68}$ and prefrontal cortex (BA 9) of MDD subjects. ${ }^{69}$ No significant changes in a set of oligodendrocyte genes selected a priori were observed in several subcortical brain regions of MDD subjects, including putamen, internal capsule and two thalamic nuclei, ${ }^{70}$ suggesting selective corticolimbic-specific and potentially other region-specific oligodendrocyte disruptions in MDD. Other a priori studies of myelin-associated genes revealed reductions in neurite outgrowth inhibitor isoform B mRNA in the frontal cortex of MDD subjects, ${ }^{71}$ reductions in Quaking protein (an oligodendrocyteassociated RNA-binding protein) in the cortex, hippocampus and amygdala of MDD subjects ${ }^{72}$ and downregulation of MBP in the anterior frontal cortex of MDD subjects. ${ }^{73}$

Areas of local demyelination appear on magnetic resonance imaging scans as white matter hyperintensities (WMH). WMHs are associated with normal aging, but are thought to be particularly prevalent in MDD subjects (reviewed in O'Brien et al. ${ }^{74}$ ). Studies using in vitro magnetic resonance imaging on postmortem elderly human MDD subjects revealed that these $\mathrm{WMH}$ may be due to vascular problems leading to cerebral ischemia and eventual white matter lesions, in support of a 'vascular depression' hypothesis. ${ }^{75}$ There is also an extensive literature of magnetic resonance imaging studies in live MDD subjects, which have revealed abnormalities in white matter (reviewed in Tham et al. ${ }^{43}$ ). Briefly, patients with late onset depression (after age 45) have more frequent and intense WMHs compared with early onset subjects, suggesting that neuropathological changes in white matter may underlie late onset depression, but not early onset depression. ${ }^{76} \mathrm{WMHs}$ are also associated with cognitive impairments in late-life depression, ${ }^{77}$ and elderly MDD subjects with more pronounced $\mathrm{WMH}$ have more severe longitudinal courses of depression, ${ }^{78}$ suggesting that WMHs could serve as markers for clinical MDD diagnoses. Diffusion tensor imaging studies have also revealed white matter abnormalities, particularly in elderly subjects with late-life MDD (reviewed in Tham et al. ${ }^{43}$ and Sexton et al. ${ }^{79}$ ). White matter fractional anisotropy, a measure of tract alignment and integrity, is consistently reduced in frontal and temporal regions in MDD subjects, ${ }^{80,81}$ is higher in antidepressant-resistant subjects, ${ }^{82}$ and is increased following electroconvulsive therapy (ECT) ${ }^{83}$ More recent diffusion tensor imaging studies in young MDD subjects have also revealed altered white matter integrity. ${ }^{84}$

Oligodendrocyte changes in animal models of MDD. Evidence implicating decreased oligodendrocyte components in MDD is paralleled by several studies in rodent models. Rodents exposed to chronic stress show a reduction in the proliferation of oligodendrocytes and NG2 + cells in the frontal cortex, a pattern that is reversible with antidepressant treatment. ${ }^{85,86}$ Similarly, chronic corticosterone stress hormone exposure in rodents resulted in decreased cortical and amygdala oligodendrocyte ${ }^{86}$ and NG2 + cell proliferation, ${ }^{64,87}$ together suggesting that oligodendrocytes may be particularly susceptible to stress-related and corticosterone-induced toxicity. Following electroconvulsive seizures, a rat model for ECT in humans, nonstressed rats showed increased proliferation of NG2 + cells in amygdala and hippocampus ${ }^{64,88,89}$ and increased proliferation of mature oligodendrocyte cells in the frontal cortex. ${ }^{90}$ In addition, similar to human studies, oligodendrocyte transcripts were selectively downregulated in the amygdala of mice exposed to unpredictable chronic mild stress and these changes were reversed by two types of antidepressant treatments. ${ }^{91}$ Interestingly, nonstressed rats or mice treated chronically with the antidepressant fluoxetine displayed no changes in oligodendrocyte proliferation in prelimbic cortex ${ }^{92}$ or in oligodendrocyterelated gene expression in cingulate cortex and amygdala, ${ }^{91}$ suggesting that oligodendrocyte changes are specific to chronic stress-induced pathology and may not be involved in the mechanism of pharmacological antidepressant treatment.

\section{Oligodendrocytes and neurons: a disease-prone bidirectional balance?}

New reports suggest that proper neuronal function depends on a bidirectional balance between myelin and axons. This may be a critical element that is disrupted in neuropsychiatric disorders. 
Potential mechanisms leading to oligodendrocyte alterations in neuropsychiatric disorders. Although it is clear that oligodendrocyte deficits are frequently observed in neuropsychiatric disorders, the actual mechanisms that induce oligodendrocyte alterations in the human brain remain unknown; however, several models have been proposed: (1) disturbances in chromatin regulation are implicated in MDD ${ }^{93}$ and are suggested to lead to disruption of oligodendrocyte differentiation and/or excitotoxicity; ${ }^{94}$ (2) oligodendrocytes express AMPA and kainate type glutamate receptors, and are thought to be sensitive to excitotoxic damage from excessive glutamate-mediated activation; ${ }^{95}$ (3) the hypothalamicpituitary-adrenal axis is disrupted in $\mathrm{MDD}^{96}$ and glucocorticoids target oligodendrocytes ${ }^{97}$ leading to decreased proliferation, ${ }^{86,87}$ suggesting that glucocorticoid-mechanisms are involved in oligodendrocyte-related pathology; and (4) finally, disruptions in dopaminergic transmission in $\mathrm{MDD}^{98}$ could also interfere with oligodendrocyte maturation via the expression of D2 and D3 receptors on oligodendrocytes. ${ }^{99}$ Notably, most current models converge on oligodendrocytes being vulnerable to stress-related insults, suggesting that these changes may be more frequent in MDD, owing to the prevalent role of stress in precipitating MDD. This notion provides support for the hypothesis that oligodendrocyterelated changes are not specific to a particular psychiatric disorder, and in fact may correspond to a cellular endophenotype that is frequently observed across stress-related and mental disorders. Hence, characterizing the etiological causes and functional consequences of oligodendrocyte dysregulations may have implications for major mental illnesses at large.

Oligodendrocyte alterations elicit functional consequences in neurons. The functional and mechanistic consequences of disrupted oligodendrocyte structure are poorly characterized, and it is not known whether they could elicit downstream consequences related to mood disorders. Although all glial cell types are important mediators of neuronal function, increasing evidence is pointing toward oligodendrocytes as a crucial component in the maintenance of axonal integrity. 5,100 One of the primary functions of oligodendrocytes is to promote axonal conduction and to actively regulate neuronal properties. ${ }^{11}$ However, oligodendrocytes also monitor neural activity through a variety of receptors including glutamatergic (AMPA, NMDA, and kainate) and GABAergic $\left(\mathrm{GABA}_{\mathrm{A}}\right)$ receptors, which both depolarize the cell, the latter is caused due to high intracellular levels of $\mathrm{Cl}^{-}$at rest (reviewed in Verkhratsky and Butt $^{9}$ ). For instance, activation of glutamate receptors on oligodendrocytes leads to depolarization of the cell, an action that rapidly modulates axonal conduction velocity. ${ }^{101,102}$ In turn, action potentials in the ensheathed axons can stimulate depolarization of oligodendrocytes. ${ }^{101}$

Direct manipulation of myelin structure also leads to alterations in neuronal properties. Cuprizone, a copper chelator, which causes global demyelination in rodents when administered orally, alters the distribution of ion channels at the critical nodal region, ${ }^{103}$ and produces changes in axonal conduction velocity. ${ }^{104}$ Mice deficient in PLP, an oligodendrocyte-specific structural protein involved in lamellae fusion, show disruption of fast axonal transport, ${ }^{105}$ while PLPoverexpressing mice have altered neuronal conduction velocity and refractory periods. ${ }^{106}$ Furthermore, mice lacking structural myelin components, including PLP, CNP, and myelin-associated glycoprotein, all have relatively normal myelin assembly, but develop progressive neurodegeneration (reviewed in Nave and Trapp ${ }^{107}$ ), pointing toward myelin as a regulator of axon trophic support. Nave and colleagues have proposed that trophic support from oligodendrocytes (for example, metabolites or neurotrophic factors) is required for mitochondrial energy metabolism in axons, as the myelin sheath itself restricts axonal access to extracellular metabolic substrates. ${ }^{5,108}$ Thus, oligodendrocyte disruptions may cause reduced metabolic coupling between the myelin and the axon, leading to structural and functional impairments.

\section{Alterations in oligodendrocytes elicit mood-related symptoms in rodents}

Whether the previously described decreased oligodendrocyte components in neuropsychiatric illnesses and rodent models of the disorder are causal to the behavioral phenotype is unknown. To address this question, several studies have used chemically induced lesions or genetic manipulations to investigate the behavioral consequences of oligodendrocyte disruption.

Chemical lesions. The cuprizone model of demyelination in mice has mainly been utilized in schizophrenia-related behavioral studies. ${ }^{109}$ Mice treated with cuprizone show reduced anxiety-like behavior in the open field and elevated plus maze tests, decreased social interaction, decreased pre-pulse inhibition, less spontaneous alternation in the Y-maze and decreased motor coordination. ${ }^{110-112}$ Cuprizone treatment also causes deficits in frontal cortexmediated cognitive tasks in rats along with decreased oligodendrocyte transcripts specifically in prefrontal regions (not hippocampus or striatum). ${ }^{113}$ However, the cuprizone model induces widespread demyelination in the brain and causes severe locomotor, social and cognitive consequences that could confound behavioral tasks, together making it difficult to discern emotionality changes specific to myelin disruption. Another demyelinating agent, lysolecithin, induced anxiety-like behaviors in the elevated plus maze and open field tests along with hyperactivity when injected directly into the hippocampus. ${ }^{114}$ Furthermore, early weaning induces anxiety-like behaviors in adulthood that are associated with alterations in whole-brain MBP expression ${ }^{115}$ and early myelin formation, specifically in the amygdala of male, but not female mice. ${ }^{116}$ Together, this evidence indicates that demyelination can influence anxiety- and depression-related behaviors (i.e. emotionality) in rodents.

Genetic approaches. Similar to rodents with chemically induced lesions, mice mutant for certain oligodendrocytespecific genes (e.g. MBP, MOBP, CASPR, CNP1) also display altered locomotor activity and motor coordination deficits. 5,107 However, emotionality behaviors have rarely been examined in these mutants. Our laboratory recently tested the potential mechanistic link between altered oligodendrocyte function and emotionality in mice by 
thoroughly examining behavioral characteristics in mice lacking CNP1 $\left(\mathrm{CNP}_{1}{ }^{\mathrm{KO}}\right)$, an oligodendrocyte-specific gene that is localized to the paranode and that has previously been implicated in $\mathrm{MDD}^{67}$ and schizophrenia. ${ }^{117-119} \mathrm{CNP} 1^{\mathrm{KO}}$ mice display motor coordination deficits beginning at 7-9 months of age. ${ }^{120,121}$ Therefore, we examined emotionality-related behaviors before the onset of these deficits in order to avoid those potential confounding effects. We found that CNP1 ${ }^{\mathrm{KO}}$ mice display a progressive age-related (3, 6 and 9 months) decrease in emotionality (anxiety- and depressive-like behaviors) under nonstressed conditions. ${ }^{120}$ Interestingly, young (3- and 6-months old) $\mathrm{CNP}_{1}^{\mathrm{KO}}$ mice were resistant to developing high emotionality states following exposure to either unpredictable chronic mild stress or chronic corticosterone, two well-established paradigms to induce high emotionality, with construct, face and predictive validities as rodent models of depression. ${ }^{120}$ In addition, $\mathrm{CNP}^{\mathrm{KO}}$ mice show low fear expression during the extinction phase of a fear conditioning paradigm, ${ }^{120}$ a behavior that is indicative of a disruption in emotion-related circuits. In humans, stress resilience is associated with the ability to adapt to chronic stress ${ }^{122}$ and the ability to perceive stressful events in a less threatening way. ${ }^{123}$ In addition, resilient individuals are thought to have optimal functioning of fear extinction mechanisms ${ }^{122}$ and 'an ability to quickly attenuate learned fear through a powerful extinction process'. ${ }^{124}$ Hence, the pattern of behavioral and amygdala-mediated dysfunctions observed in CNP1 ${ }^{\mathrm{KO}}$ mice suggests a phenotype characteristic of stress resilience. It is currently not known whether this apparent contradiction-low CNP in human MDD and resiliency in $\mathrm{CNP}_{1}{ }^{\mathrm{KO}}$ mice - results from maladaptive compensatory changes, or from the selective disruption in mice of a single component extracted from a broader dysregulated gene pattern in human MDD (see Edgar et al. ${ }^{120}$ for discussion). Similar to CNP1 ${ }^{\mathrm{KO}}$ mice, mice overexpressing PLP display reduced anxiety-like behaviors in the elevated plus maze, along with significantly reduced axonal conduction velocity. ${ }^{125}$

In combination with reports using chemical lesions of myelin, these data suggest that oligodendrocytes have a role in regulating stress responsiveness and that changes in oligodendrocyte structure and function can impact circuits mediating emotionality in mice; although the precise mechanisms underlying these effects are unclear. However, mouse behaviors are often difficult to interpret and categorize, and an alternative interpretation of the $\mathrm{CNP} 1^{\mathrm{KO}}$ phenotype could be a manic-like phenotype (i.e. hyperactivity and low anxietylike behaviors), more akin to aspects of bipolar disorder. Thus, studies using genetic manipulation or demyelinating agents in region- and time-specific manners, combined with functional (i.e., electrophysiology) and broader phenotypic characterizations are needed to further refine the role and contribution of oligodendrocytes in the function of neural circuits underlying mood and associated disorders.

\section{The paranode as a proposed site of dysregulation in neuropsychiatric disorders}

The paranode region of oligodendrocytes is a critical site of interaction between myelin and axons (reviewed in
Rosenbluth ${ }^{13}$ ), and recent studies investigating the putative role of oligodendrocyte alterations in psychiatric disorders, including MDD and schizophrenia, suggest that the nodal and paranodal regions of oligodendrocytes may represent important sites of dysregulation (Figure 1). 4,100,126

Ablation of paranodal proteins, such as CNP1 and CASPR, cause structural disorganization at the paranode, ${ }^{127,128}$ which could lead to electrophysiological changes in the axon. Indeed, in mice lacking CASPR, the paranode region fails to form, and these mice exhibit decreased nerve conduction velocity, ${ }^{129}$ supporting a role for the paranode region in maintaining proper axonal signal transmission. In addition, mice overexpressing PLP exhibit abnormal paranodal structure, including everted paranodal loops, lack of proper cell junctions and abnormal CASPR clustering in forebrain regions, in parallel with behavioral and electrophysiological abnormalities. ${ }^{125}$ Yamazaki et al. ${ }^{130}$ speculate that structural changes such as swelling, particularly at the paranode, could drastically alter neuronal insulation properties resulting in changes to leak currents that could impact the speed of depolarization. Conversely, repetitive action potential propagation in neurons leads to paranodal swelling, ${ }^{131}$ perhaps due to osmotic water flux, ${ }^{102}$ again highlighting the balance between axons and their myelin sheath. Structural changes to the paranode (e.g. CASPR ablation) also result in accumulation of mitochondria at the node and paranode (in peripheral samples), ${ }^{132}$ supporting Nave's hypothesis of altered metabolic coupling between the myelin and axon. ${ }^{5}$

As described above, the lack of CNP1, a paranodalassociated gene product, can impact the function of the amygdala, a critical region within a broader corticolimbic circuitry of affect-regulation and associated behaviors in mice. This evidence supports an active contribution of altered oligodendrocyte structure and function to mood-related behavioral phenotypes and symptom dimensions observed in human MDD, and possibly schizophrenia. However, the $\mathrm{CNP} 1^{\mathrm{KO}}$ rodent studies are somewhat surprising, in that they point to a potential decrease in emotionality, which may also relate to behavioral aspects of bipolar disease. Together, the data suggest a complex balance between neuron and oligodendrocyte functions in modulating the function of neural networks underlying affect regulation. The accumulated evidence points toward the paranode, as a significant structural and functional interface between axons and the myelin sheath, which may be selectively vulnerable to glucocorticoids, stress-related insults or more simply, to increased and sustained recruitment, as occurring in emotion-processing areas such as the amygdala. These events would in turn lead to altered homeostasis (e.g. osmotic and metabolic stress) at this critical region of axoglial communication. In a simplified model (Figure 1), impaired paranode integrity may lead to local cellular dysfunction and improper axonal conduction, resulting in loss of integrity of information transfer; which, in the context of amygdala dysfunction in MDD, we speculate may underlie the deregulated affectrelated phenotype.

In summary, oligodendrocytes provide critical support to neuronal function and display patterns of dysregulation in MDD, schizophrenia and bipolar disorder, which are distinct 


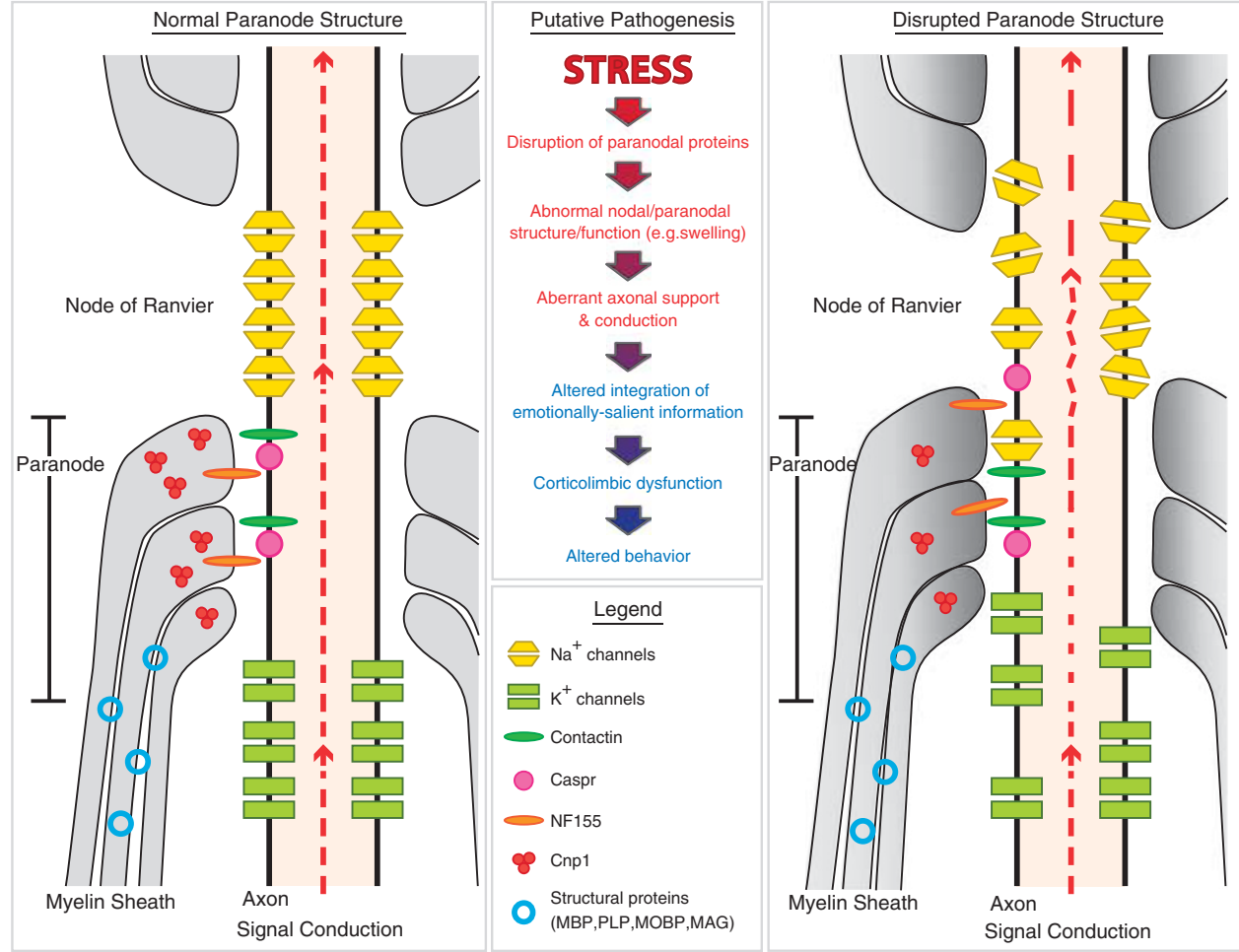

Figure 1 Schematic model of a putative stress-induced pathogenic process at the paranode and node of Ranvier. Evidence suggests that disruption of paranode molecule composition (e.g., stress or CNP1/CASPR ablation) can affect its structural integrity (Right panel: swelling (gray shading), lower junction delineation). This could lead to altered support of axonal function within the node of Ranvier, and suboptimal conduction of action potentials along the axon (dotted red line), leading to decreased integrity of information transfer, to or within, critical brain regions, such as the amygdala. In turn, the integration of this altered information (e.g., emotional stimuli) may propagate throughout the corticolimbic circuitry involved in mood regulation, ultimately resulting in abnormal integration of emotional salience, and affecting subsequent related behaviors.

from those of other glial cell subtypes. The primary evidence in the human postmortem brain demonstrates shared features across major mental illnesses, and current models of oligodendrocyte pathophysiological vulnerability converge on stress-related insults. Together, this suggests that oligodendrocyte-related changes are not specific to any psychiatric disorder, and may instead represent a cellular endophenotype that is downstream from etiological and pathophysiological events that are frequently recruited in major mental illnesses. The critical role of stress in precipitating depressive episodes may explain the more prevalent corticolimbic patterns of oligodendrocyte changes in MDD. On the other hand, emerging data from rodent studies suggest that oligodendrocyte dysfunction, including both structural and functional changes of the axoglial paranode interface, may exert modulatory roles on neural circuitry underlying mood regulation. It is conceivable that these disruptions may manifest as different phenotypes (or illnesses) depending upon the developmental timing, affected region and extent of pathophysiology. Hence, investigating the etiological factors that lead to oligodendrocyte dysfunction, and their bidirectional links with neuronal dysfunction, while characterizing the functional consequences of such disruptions, may have implications for mechanisms and treatments of symptom dimensions across major mental illnesses.

\section{Conflict of interest}

The authors declare no conflict of interest.

Acknowledgements. This work was supported by National Institute of Mental Health (NIMH) MH083410 (NE), MH084060 (ES), MH093723 (ES) and MH077159 (ES). The funding agency had no role in the study design, data collection and analysis, decision to publish and preparation of the manuscript. The content is solely the responsibility of the authors and does not necessarily represent the official views of the NIMH or the National Institutes of Health.

1. Bernstein HG, Steiner J, Bogerts B. Glial cells in schizophrenia: pathophysiological significance and possible consequences for therapy. Expert Rev Neurother 2009; 9: 1059-1071.

2. Rajkowska G, Miguel-Hidalgo JJ. Gliogenesis and glial pathology in depression. CNS Neurol Disord Drug Targets 2007; 6: 219-233.

3. Rajkowska G. Cell pathology in bipolar disorder. Bipolar Disord 2002; 4: 105-116.

4. Fields RD. White matter in learning, cognition and psychiatric disorders. Trends Neurosci 2008; 31: 361-370.

5. Nave KA. Myelination and the trophic support of long axons. Nat Rev Neurosci 2010; 11: 275-283.

6. Miller RH. Regulation of oligodendrocyte development in the vertebrate CNS. Prog Neurobiol 2002; 67: 451-467.

7. Pelvig DP, Pakkenberg H, Stark AK, Pakkenberg B. Neocortical glial cell numbers in human brains. Neurobiol Aging 2008; 29: 1754-1762.

8. Burne JF, Staple JK, Raff MC. Glial cells are increased proportionally in transgenic optic nerves with increased numbers of axons. J Neurosci 1996; 16: 2064-2073.

9. Verkhratsky A, Butt A. Glial Neurobiology: A Textbook. John Wiley \& Sons Inc: Hoboken, NJ, 2007. 
10. Jahn O, Tenzer S, Werner HB. Myelin proteomics: molecular anatomy of an insulating sheath. Mol Neurobiol 2009; 40: 55-72.

11. Poliak S, Peles E. The local differentiation of myelinated axons at nodes of Ranvier. Nat Rev Neurosci 2003; 4: 968-980.

12. Pedraza L, Huang JK, Colman DR. Organizing principles of the axoglial apparatus. Neuron 2001; 30: 335-344.

13. Rosenbluth J. Multiple functions of the paranodal junction of myelinated nerve fibers. J Neurosci Res 2009; 87: 3250-3258.

14. Pelvig DP, Pakkenberg H, Regeur L, Oster S, Pakkenberg B. Neocortical glial cell numbers in Alzheimer's disease. A stereological study. Dement Geriatr Cogn Disord 2003; 16: 212-219.

15. Berry M, Hubbard P, Butt AM. Cytology and lineage of NG2-positive glia. J Neurocytol 2002; 31: 457-467.

16. Wilson HC, Scolding NJ, Raine CS. Co-expression of PDGF alpha receptor and NG2 by oligodendrocyte precursors in human CNS and multiple sclerosis lesions. J Neuroimmunol 2006; 176: 162-173.

17. Nishiyama A, Komitova M, Suzuki R, Zhu X. Polydendrocytes (NG2 cells): multifunctional cells with lineage plasticity. Nat Rev Neurosci 2009; 10: 9-22.

18. Karadottir R, Hamilton NB, Bakiri Y, Attwell D. Spiking and nonspiking classes of oligodendrocyte precursor glia in CNS white matter. Nat Neurosci 2008; 11 450-456.

19. Patneau DK, Wright PW, Winters C, Mayer ML, Gallo V. Glial cells of the oligodendrocyte lineage express both kainate- and AMPA-preferring subtypes of glutamate receptor. Neuron 1994; 12: 357-371.

20. Smith SM, Johansen-Berg $H$, Jenkinson M, Rueckert D, Nichols TE, Miller KL et al. Acquisition and voxelwise analysis of multi-subject diffusion data with tract-based spatial statistics. Nat Protoc 2007; 2: 499-503.

21. Aston C, Jiang L, Sokolov BP. Microarray analysis of postmortem temporal cortex from patients with schizophrenia. J Neurosci Res 2004; 77: 858-866.

22. Aston C, Jiang L, Sokolov BP. Transcriptional profiling reveals evidence for signaling and oligodendroglial abnormalities in the temporal cortex from patients with major depressive disorder. Mol Psychiatry 2005; 10: 309-322.

23. Dracheva S, Davis KL, Chin B, Woo DA, Schmeidler J, Haroutunian V. Myelin-associated mRNA and protein expression deficits in the anterior cingulate cortex and hippocampus in elderly schizophrenia patients. Neurobiol Dis 2006; 21: 531-540.

24. Katsel P, Davis KL, Haroutunian V. Variations in myelin and oligodendrocyte-related gene expression across multiple brain regions in schizophrenia: a gene ontology study. Schizophr Res 2005; 79: 157-173.

25. Tkachev D, Mimmack ML, Ryan MM, Wayland M, Freeman T, Jones PB et al. Oligodendrocyte dysfunction in schizophrenia and bipolar disorder. Lancet 2003; 362 798-805.

26. Uranova NA, Vostrikov VM, Orlovskaya DD, Rachmanova VI. Oligodendroglial density in the prefrontal cortex in schizophrenia and mood disorders: a study from the Stanley Neuropathology Consortium. Schizophr Res 2004; 67: 269-275.

27. Hof PR, Haroutunian V, Friedrich Jr VL, Byne W, Buitron C, Perl DP et al. Loss and altered spatial distribution of oligodendrocytes in the superior frontal gyrus in schizophrenia. Biol Psychiatry 2003; 53: 1075-1085.

28. Stark AK, Uylings HB, Sanz-Arigita E, Pakkenberg B. Glial cell loss in the anterio cingulate cortex, a subregion of the prefrontal cortex, in subjects with schizophrenia. Am Psychiatry 2004; 161: 882-888.

29. Uranova N, Orlovskaya D, Vikhreva O, Zimina I, Kolomeets N, Vostrikov V et al. Electron microscopy of oligodendroglia in severe mental illness. Brain Res Bull 2001; 55 597-610.

30. Takahashi N, Sakurai T, Davis KL, Buxbaum JD. Linking oligodendrocyte and myelin dysfunction to neurocircuitry abnormalities in schizophrenia. Prog Neurobiol 2011; 93 : 13-24.

31. Katsel P, Davis KL, Li C, Tan W, Greenstein E, Kleiner Hoffman LB et al. Abnormal indices of cell cycle activity in schizophrenia and their potential association with oligodendrocytes. Neuropsychopharmacology 2008; 33: 2993-3009.

32. Haroutunian V, Katsel P, Dracheva S, Stewart DG, Davis KL. Variations in oligodendrocyte-related gene expression across multiple cortical regions: implications for the pathophysiology of schizophrenia. Int J Neuropsychopharmacol 2007; 10 565-573.

33. Carter CJ. Multiple genes and factors associated with bipolar disorder converge on growth factor and stress activated kinase pathways controlling translation initiation: implications for oligodendrocyte viability. Neurochem Int 2007; 50 : 461-490.

34. Iwamoto K, Kakiuchi C, Bundo M, Ikeda K, Kato T. Molecular characterization of bipolar disorder by comparing gene expression profiles of postmortem brains of major mental disorders. Mol Psychiatry 2004; 9: 406-416.

35. Regenold WT, Phatak P, Marano CM, Gearhart L, Viens CH, Hisley KC. Myelin staining of deep white matter in the dorsolateral prefrontal cortex in schizophrenia, bipolar disorder and unipolar major depression. Psychiatry Res 2007; 151: 179-188.

36. McIntosh AM, Hall J, Lymer GK, Sussmann JE, Lawrie SM. Genetic risk for white matter abnormalities in bipolar disorder. Int Rev Psychiatry 2009; 21: 387-393.

37. Mahon K, Burdick KE, Szeszko PR. A role for white matter abnormalities in the pathophysiology of bipolar disorder. Neurosci Biobehav Rev 2010; 34: 533-554.
38. Davis KL, Stewart DG, Friedman JI, Buchsbaum M, Harvey PD, Hof PR et al. White matter changes in schizophrenia: evidence for myelin-related dysfunction. Arch Gen Psychiatry 2003; 60: 443-456.

39. Chwastiak LA, Ehde DM. Psychiatric issues in multiple sclerosis. Psychiatr Clin North Am 2007; 30: 803-817.

40. Joffe RT, Lippert GP, Gray TA, Sawa G, Horvath Z. Mood disorder and multiple sclerosis. Arch Neurol 1987; 44: 376-378.

41. Konradi C, Sillivan SE, Clay HB. Mitochondria, oligodendrocytes and inflammation in bipolar disorder: evidence from transcriptome studies points to intriguing parallels with multiple sclerosis. Neurobiol Dis 2011; 45: 37-47.

42. Hercher C, Turecki G, Mechawar N. Through the looking glass: examining neuroanatomical evidence for cellular alterations in major depression. J Psychiatr Res 2009; 43: 947-961.

43. Tham MW, Woon PS, Sum MY, Lee TS, Sim K. White matter abnormalities in major depression: evidence from post-mortem, neuroimaging and genetic studies. J Affect Disord 2011; 132: 26-36.

44. Sacher J, Neumann J, Funfstuck T, Soliman A, Villringer A, Schroeter ML. Mapping the depressed brain: a meta-analysis of structural and functional alterations in major depressive disorder; J Affect Disord advance online publication, 2 September 2011 (e-pub ahead of print).

45. Ongur D, Drevets WC, Price JL. Glial reduction in the subgenual prefrontal cortex in mood disorders. Proc Natl Acad Sci USA 1998; 95: 13290-13295.

46. Rajkowska G, Miguel-Hidalgo JJ, Wei J, Dilley G, Pittman SD, Meltzer HY et al. Morphometric evidence for neuronal and glial prefrontal cell pathology in major depression. Biol Psychiatry 1999; 45: 1085-1098.

47. Cotter D, Mackay D, Chana G, Beasley C, Landau S, Everall IP. Reduced neuronal size and glial cell density in area 9 of the dorsolateral prefrontal cortex in subjects with major depressive disorder. Cereb Cortex 2002; 12: 386-394.

48. Cotter D, Mackay D, Landau S, Kerwin R, Everall I. Reduced glial cell density and neuronal size in the anterior cingulate cortex in major depressive disorder. Arch Gen Psychiatry 2001; 58: 545-553.

49. Bowley MP, Drevets WC, Ongur D, Price JL. Low glial numbers in the amygdala in major depressive disorder. Biol Psychiatry 2002; 52: 404-412.

50. Hamidi M, Drevets WC, Price JL. Glial reduction in amygdala in major depressive disorder is due to oligodendrocytes. Biol Psychiatry 2004; 55: 563-569.

51. Chana G, Landau S, Beasley C, Everall IP, Cotter D. Two-dimensional assessment of cytoarchitecture in the anterior cingulate cortex in major depressive disorder, bipolar disorder, and schizophrenia: evidence for decreased neuronal somal size and increased neuronal density. Biol Psychiatry 2003; 53: 1086-1098.

52. Schroeter ML, Steiner J, Mueller K. Glial pathology is modified by age in mood disorders a systematic meta-analysis of serum S100B in vivo studies. J Affect Disord 2011; 134: $32-38$.

53. Khundakar A, Morris C, Oakley A, McMeekin W, Thomas AJ. Morphometric analysis of neuronal and glial cell pathology in the dorsolateral prefrontal cortex in late-life depression. Br J Psychiatry 2009; 195: 163-169.

54. Khundakar A, Morris C, Oakley A, Thomas AJ. A morphometric examination of neuronal and glial cell pathology in the orbitofrontal cortex in late-life depression. Int Psychogeriatr 2011; 23: 132-140.

55. Miguel-Hidalgo JJ, Baucom C, Dilley G, Overholser JC, Meltzer HY, Stockmeier CA et al. Glial fibrillary acidic protein immunoreactivity in the prefrontal cortex distinguishes younger from older adults in major depressive disorder. Biol Psychiatry 2000; 48: 861-873.

56. Miguel-Hidalgo JJ, Waltzer R, Whittom AA, Austin MC, Rajkowska G, Stockmeier CA. Glial and glutamatergic markers in depression, alcoholism, and their comorbidity. J Affect Disord 2010; 127: 230-240.

57. Si X, Miguel-Hidalgo JJ, O'Dwyer G, Stockmeier CA, Rajkowska G. Age-dependent reductions in the level of glial fibrillary acidic protein in the prefrontal cortex in major depression. Neuropsychopharmacology 2004; 29: 2088-2096.

58. Torres-Platas SG, Hercher C, Davoli MA, Maussion G, Labonte B, Turecki G et al. Astrocytic hypertrophy in anterior cingulate white matter of depressed suicides. Neuropsychopharmacology 2011; 36: 2650-2658.

59. Banasr M, Chowdhury GM, Terwilliger R, Newton SS, Duman RS, Behar KL et al. Glia pathology in an animal model of depression: reversal of stress-induced cellular, metabolic and behavioral deficits by the glutamate-modulating drug riluzole. Mol Psychiatry 2010; 15: $501-511$

60. Banasr M, Duman RS. Glial loss in the prefrontal cortex is sufficient to induce depressivelike behaviors. Biol Psychiatry 2008; 64: 863-870.

61. Czeh B, Simon M, Schmelting B, Hiemke C, Fuchs E. Astroglial plasticity in the hippocampus is affected by chronic psychosocial stress and concomitant Fluoxetine treatment. Neuropsychopharmacology 2006; 31: 1616-1626.

62. Valentine GW, Sanacora G. Targeting glial physiology and glutamate cycling in the treatment of depression. Biochem Pharmacol 2009; 78: 431-439.

63. Steiner J, Bielau H, Brisch R, Danos P, Ullrich O, Mawrin C et al. Immunological aspects in the neurobiology of suicide: elevated microglial density in schizophrenia and depression is associated with suicide. J Psychiatr Res 2008; 42: 151-157.

64. Wennstrom M, Hellsten J, Ekstrand J, Lindgren H, Tingstrom A. Corticosterone-induced inhibition of gliogenesis in rat hippocampus is counteracted by electroconvulsive seizures. Biol Psychiatry 2006; 59: 178-186. 
65. Schnieder TP, Dwork AJ. Searching for neuropathology: gliosis in schizophrenia. Biol Psychiatry 2011; 69: 134-139.

66. Hayashi Y, Nihonmatsu-Kikuchi N, Yu X, Ishimoto K, Hisanaga SI, Tatebayashi Y. A novel, rapid, quantitative cell-counting method reveals oligodendroglial reduction in the frontopolar cortex in major depressive disorder. Mol Psychiatry 2011; 16 $1155-1158$.

67. Sibille E, Wang Y, Joeyen-Waldorf J, Gaiteri C, Surget A, Oh S et al. A molecular signature of depression in the amygdala. Am J Psychiatry 2009; 166: 1011-1024.

68. Klempan TA, Sequeira A, Canetti L, Lalovic A, Ernst C, ffrench-Mullen J et al. Altered expression of genes involved in ATP biosynthesis and GABAergic neurotransmission in the ventral prefrontal cortex of suicides with and without major depression. Mol Psychiatry 2009; 14: 175-189.

69. Kim S, Webster MJ. Correlation analysis between genome-wide expression profiles and cytoarchitectural abnormalities in the prefrontal cortex of psychiatric disorders. Mol Psychiatry 2010; 15: 326-336.

70. Barley K, Dracheva S, Byne W. Subcortical oligodendrocyte- and astrocyte-associated gene expression in subjects with schizophrenia, major depression and bipolar disorder. Schizophr Res 2009; 112: 54-64.

71. Novak G, Tallerico T. Nogo A, B and C expression in schizophrenia, depression and bipolar frontal cortex, and correlation of Nogo expression with CAA/TATC polymorphism in $3^{\prime}$-UTR. Brain Res 2006; 1120: 161-171.

72. Klempan TA, Ernst C, Deleva V, Labonte B, Turecki G. Characterization of QKI gene expression, genetics, and epigenetics in suicide victims with major depressive disorder. Biol Psychiatry 2009; 66: 824-831.

73. Honer WG, Falkai P, Chen C, Arango V, Mann JJ, Dwork AJ. Synaptic and plasticityassociated proteins in anterior frontal cortex in severe mental illness. Neuroscience 1999; 91: 1247-1255.

74. O'Brien JT, Ames D, Schwietzer I. White Matter Changes in Depression and Alzheimer's Disease: A Review of Magnetic Resonance Imaging Studies, Vol. 11. John Wiley \& Sons, Ltd, 1996, pp 681-694.

75. Thomas AJ, O'Brien JT, Davis S, Ballard C, Barber R, Kalaria RN et al. Ischemic basis for deep white matter hyperintensities in major depression: a neuropathological study. Arch Gen Psychiatry 2002; 59: 785-792.

76. Herrmann LL, Le Masurier M, Ebmeier KP. White matter hyperintensities in late life depression: a systematic review. J Neurol Neurosurg Psychiatry 2008; 79: 619-624.

77. Kohler S, Thomas AJ, Lloyd A, Barber R, Almeida OP, O'Brien JT. White matter hyperintensities, cortisol levels, brain atrophy and continuing cognitive deficits in late-life depression. Br J Psychiatry 2010; 196: 143-149.

78. Heiden A, Kettenbach J, Fischer P, Schein B, Ba-Ssalamah A, Frey R et al. White matter hyperintensities and chronicity of depression. J Psychiatr Res 2005; 39: 285-293.

79. Sexton CE, Mackay CE, Ebmeier KP. A systematic review of diffusion tensor imaging studies in affective disorders. Biol Psychiatry 2009; 66: 814-823.

80. Bae JN, MacFall JR, Krishnan KR, Payne ME, Steffens DC, Taylor WD. Dorsolateral prefrontal cortex and anterior cingulate cortex white matter alterations in late-life depression. Biol Psychiatry 2006; 60: 1356-1363.

81. Taylor WD, MacFall JR, Payne ME, McQuoid DR, Provenzale JM, Steffens DC et al. Latelife depression and microstructural abnormalities in dorsolateral prefrontal cortex white matter. Am J Psychiatry 2004; 161: 1293-1296.

82. Taylor WD, Kuchibhatla M, Payne ME, Macfall JR, Sheline YI, Krishnan KR et al. Frontal white matter anisotropy and antidepressant remission in late-life depression. PLoS One 2008; 3: e3267.

83. Nobuhara K, Okugawa G, Minami T, Takase K, Yoshida T, Yagyu T et al. Effects of electroconvulsive therapy on frontal white matter in late-life depression: a diffusion tensor imaging study. Neuropsychobiology 2004; 50: 48-53.

84. Ma N, Li L, Shu N, Liu J, Gong G, He Z et al. White matter abnormalities in first-episode, treatment-naive young adults with major depressive disorder. Am J Psychiatry 2007; 164 823-826.

85. Czeh B, Muller-Keuker JI, Rygula R, Abumaria N, Hiemke C, Domenici E et al. Chronic social stress inhibits cell proliferation in the adult medial prefrontal cortex: hemispheric asymmetry and reversal by fluoxetine treatment. Neuropsychopharmacology 2007; 32 1490-1503.

86. Banasr M, Valentine GW, Li XY, Gourley SL, Taylor JR, Duman RS. Chronic unpredictable stress decreases cell proliferation in the cerebral cortex of the adult rat. Biol Psychiatry 2007; 62: 496-504.

87. Alonso G. Prolonged corticosterone treatment of adult rats inhibits the proliferation of oligodendrocyte progenitors present throughout white and gray matter regions of the brain. Glia 2000; 31: 219-231.

88. Wennstrom M, Hellsten J, Ekdahl CT, Tingstrom A. Electroconvulsive seizures induce proliferation of NG2-expressing glial cells in adult rat hippocampus. Biol Psychiatry 2003; 54: 1015-1024.

89. Wennstrom M, Hellsten J, Tingstrom A. Electroconvulsive seizures induce proliferation of NG2-expressing glial cells in adult rat amygdala. Biol Psychiatry 2004; 55: 464-471.

90. Madsen TM, Yeh DD, Valentine GW, Duman RS. Electroconvulsive seizure treatment increases cell proliferation in rat frontal cortex. Neuropsychopharmacology 2005 30: $27-34$

91. Surget A, Wang Y, Leman S, Ibarguen-Vargas Y, Edgar N, Griebel G et al. Corticolimbic transcriptome changes are state-dependent and region-specific in a rodent model of depression and of antidepressant reversal. Neuropsychopharmacology 2008; 34 1363-1380.

92. Kodama M, Fujioka T, Duman RS. Chronic olanzapine or fluoxetine administration increases cell proliferation in hippocampus and prefrontal cortex of adult rat. Biol Psychiatry 2004; 56: 570-580.

93. Hobara T, Uchida S, Otsuki K, Matsubara T, Funato H, Matsuo K et al. Altered gene expression of histone deacetylases in mood disorder patients. J Psychiatr Res 2010; 44 263-270.

94. Sokolov BP. Oligodendroglial abnormalities in schizophrenia, mood disorders and substance abuse. Comorbidity, shared traits, or molecular phenocopies? Int $\mathrm{J}$ Neuropsychopharmacol 2007; 10: 547-555.

95. McDonald JW, Levine JM, Qu Y. Multiple classes of the oligodendrocyte lineage are highly vulnerable to excitotoxicity. Neuroreport 1998; 9: 2757-2762.

96. McEwen BS. Physiology and neurobiology of stress and adaptation: central role of the brain. Physiol Rev 2007; 87: 873-904.

97. Cheng JD, de Vellis J. Oligodendrocytes as glucocorticoids target cells: functional analysis of the glycerol phosphate dehydrogenase gene. J Neurosci Res 2000 59: $436-445$.

98. Nestler EJ, Carlezon Jr WA. The mesolimbic dopamine reward circuit in depression. Biol Psychiatry 2006; 59: 1151-1159.

99. Bongarzone ER, Howard SG, Schonmann V, Campagnoni AT. Identification of the dopamine D3 receptor in oligodendrocyte precursors: potential role in regulating differentiation and myelin formation. J Neurosci 1998; 18: 5344-5353.

100. Nave KA. Myelination and support of axonal integrity by glia. Nature 2010; 468 244-252.

101. Yamazaki $\mathrm{Y}$, Hozumi $\mathrm{Y}$, Kaneko K, Sugihara T, Fujii S, Goto $\mathrm{K}$ et al. Modulatory effects of oligodendrocytes on the conduction velocity of action potentials along axons in the alveus of the rat hippocampal CA1 region. Neuron Glia Biol 2007; 3 : 325-334.

102. Karadottir R, Cavelier $P$, Bergersen LH, Attwell D. NMDA receptors are expressed in oligodendrocytes and activated in ischaemia. Nature 2005; 438: 1162-1166.

103. Dupree JL, Mason JL, Marcus JR, Stull M, Levinson R, Matsushima GK et al Oligodendrocytes assist in the maintenance of sodium channel clusters independent of the myelin sheath. Neuron Glia Biol 2004; 1: 179-192.

104. Bando Y, Takakusaki K, Ito S, Terayama R, Kashiwayanagi M, Yoshida S. Differentia changes in axonal conduction following CNS demyelination in two mouse models. European Journal of Neuroscience 2008; 28: 1731-1742.

105. Edgar JM, McLaughlin M, Yool D, Zhang SC, Fowler JH, Montague $\mathrm{P}$ et al. Oligodendroglial modulation of fast axonal transport in a mouse model of hereditary spastic paraplegia. J Cell Biol 2004; 166: 121-131

106. Tanaka $\mathrm{H}$, Ikenaka $\mathrm{K}$, Isa $\mathrm{T}$. Electrophysiological abnormalities precede apparent histological demyelination in the central nervous system of mice overexpressing proteolipid protein. J Neurosci Res 2006; 84: 1206-1216.

107. Nave KA, Trapp BD. Axon-glial signaling and the glial support of axon function. Annu Rev Neurosci 2008; 31: 535-561.

108. Edgar JM, Nave KA. The role of CNS glia in preserving axon function. Curr Opin Neurobiol 2009; 19: 498-504.

109. Herring NR, Konradi C. Myelin, copper, and the cuprizone model of schizophrenia. Front Biosci (Schol Ed) 2011; 3: 23-40.

110. Franco-Pons N, Torrente M, Colomina MT, Vilella E. Behavioral deficits in the cuprizoneinduced murine model of demyelination/remyelination. Toxicol Lett 2007; 169 205-213.

111. Xu H, Yang H-J, Zhang Y, Clough R, Browning R, Li X-M. Behavioral and neurobiological changes in C57BL/6 mice exposed to cuprizone. Behav Neurosci 2009; 123 418-429.

112. Xu H, Yang HJ, McConomy B, Browning R, Li XM. Behavioral and neurobiological changes in C57BL/6 mouse exposed to cuprizone: effects of antipsychotics. Front Behav Neurosci 2010; 4: 8.

113. Gregg JR, Herring NR, Naydenov AV, Hanlin RP, Konradi C. Downregulation of oligodendrocyte transcripts is associated with impaired prefrontal cortex function in rats. Schizophr Res 2009; 113: 277-287.

114. Makinodan M, Tatsumi K, Okuda H, Manabe T, Yamauchi T, Noriyama $Y$ et al. Lysophosphatidylcholine induces delayed myelination in the juvenile ventral hippocampus and behavioral alterations in adulthood. Neurochem Int 2008; 53 374-381.

115. Kikusui $T$, Kiyokawa $Y$, Mori $Y$. Deprivation of mother-pup interaction by early weaning alters myelin formation in male, but not female, ICR mice. Brain Res 2007; 1133: 115-122.

116. Ono M, Kikusui T, Sasaki N, Ichikawa M, Mori Y Murakami-Murofushi K Early weaning induces anxiety and precocious myelination in the anterior part of the basolatera amygdala of male Balb/c mice. Neuroscience 2008; 156: 1103-1110.

117. Peirce TR, Bray NJ, Williams NM, Norton N, Moskvina V, Preece A et al. Convergen evidence for $2^{\prime}, 3^{\prime}$-cyclic nucleotide $3^{\prime}$-phosphodiesterase as a possible susceptibility gene for schizophrenia. Arch Gen Psychiatry 2006; 63: 18-24.

118. Tang F, Qu M, Wang L, Ruan Y, Lu T, Zhang H et al. Case-control association study of the $2^{\prime}, 3^{\prime}$-cyclic nucleotide $3^{\prime}$-phosphodiesterase (CNP) gene and schizophrenia in the Han Chinese population. Neurosci Lett 2007; 416: 113-116. 
119. Iwamoto $\mathrm{K}$, Ueda J, Bundo $\mathrm{M}$, Nakano $\mathrm{Y}$, Kato $\mathrm{T}$. Effect of a functional single nucleotide polymorphism in the $2^{\prime}, 3^{\prime}$-cyclic nucleotide $3^{\prime}$-phosphodiesterase gene on the expression of oligodendrocyte-related genes in schizophrenia. Psychiatry Clin Neurosci 2008; 62 103-108.

120. Edgar NM, Touma C, Palme R, Sibille E. Resilient emotionality and molecular compensation in mice lacking the oligodendrocyte-specific gene Cnp1. Transl Psychiatry 2011; 1 : e42.

121. Lappe-Siefke C, Goebbels S, Gravel M, Nicksch E, Lee J, Braun PE et al. Disruption of Cnp1 uncouples oligodendroglial functions in axonal support and myelination. Nat Genet 2003; 33: 366-374.

122. Feder A, Nestler EJ, Charney DS. Psychobiology and molecular genetics of resilience. Nat Rev Neurosci 2009; 10: 446-457.

123. Southwick SM, Vythilingam M, Charney DS. The psychobiology of depression and resilience to stress: implications for prevention and treatment. Annu Rev Clin Psychol 2005; 1: 255-291.

124. Charney DS. Psychobiological mechanisms of resilience and vulnerability: implications for successful adaptation to extreme stress. Am J Psychiatry 2004; 161 195-216.

125. Tanaka H, Ma J, Tanaka KF, Takao K, Komada M, Tanda K et al. Mice with altered myelin proteolipid protein gene expression display cognitive deficits accompanied by abnormal neuron-glia interactions and decreased conduction velocities. J Neurosci 2009 29: 8363-8371.

126. Roussos P, Katsel P, Davis KL, Bitsios P, Giakoumaki SG, Jogia J et al. Molecular and genetic evidence for abnormalities in the nodes of Ranvier in schizophrenia. Arch Gen Psychiatry 2011; 69: 7-15.
127. Sun XY, Takagishi $Y$, Okabe E, Chishima Y, Kanou Y, Murase S et al. A novel Caspr mutation causes the shambling mouse phenotype by disrupting axoglial interactions of myelinated nerves. J Neuropathol Exp Neurol 2009; 68: 1207-1218.

128. Rasband MN, Tayler J, Kaga Y, Yang Y, Lappe-Siefke C, Nave KA et al. CNP is required for maintenance of axon-glia interactions at nodes of Ranvier in the CNS. Glia 2005; 50: $86-90$

129. Bhat MA, Rios JC, Lu Y, Garcia-Fresco GP, Ching W, St Martin M et al. Axon-glia interactions and the domain organization of myelinated axons requires neurexin IV/Caspr/ Paranodin. Neuron 2001; 30: 369-383.

130. Yamazaki Y, Hozumi Y, Kaneko K, Fujii S, Goto K, Kato H. Oligodendrocytes: facilitating axonal conduction by more than myelination. Neuroscientist 2010; 16: 11-18.

131. Wurtz CC, Ellisman MH. Alterations in the ultrastructure of peripheral nodes of Ranvier associated with repetitive action potential propagation. J Neurosci 1986; 6 : 3133-3143.

132. Einheber S, Bhat MA, Salzer JL. Disrupted Axo-Glial junctions result in accumulation of abnormal mitochondria at Nodes of Ranvier. Neuron Glia Biol 2006; 2: 165-174.

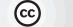

Translational Psychiatry is an open-access journal published by Nature Publishing Group. This work is licensed under the Creative Commons Attribution-Noncommercial-No Derivative Works 3.0 Unported License. To view a copy of this license, visit http://creativecommons.org/licenses/by-nc-nd/3.0/ 